\title{
Dose-response curves for co-exposure inhalation challenges with ozone and pollen allergen
}

\author{
To the Editor:
}

Exposures to pollen and air pollutants commonly occur simultaneously and have been linked to eliciting or exacerbating the allergic response in susceptible individuals $[1,2]$. The risk of co-exposure was recently confirmed in a study from Copenhagen, Denmark [3] indicating that pollen and ozone concentration peaks coincide both diurnally and seasonally. Ozone exposures are able to prime the airways and exacerbate respiratory symptoms [4]. However, this effect is debated, especially regarding lower and more commonly naturally occurring exposures $[5,6]$.

Here we present a study aiming to investigate whether short-term exposure to pollen allergen simultaneous to naturally occurring levels of ozone increases the bronchoconstrictive response during specific inhalation challenge (SIC).

The participants had allergic rhinitis and no or mild asthma, thus representing the majority of pollen-sensitised subjects.

We included 36 non-smoking students (20 females, 16 males, mean age 24 years) with a history of allergic rhinitis and a positive skin allergy test above $3 \mathrm{~mm}$ to birch and/or grass. Among these, 20 reported respiratory symptoms (cough, wheeze, chest tightness) more than twice per year, and 10 reported mild asthma but did not use asthma medication.

The study was performed as a randomised single blinded cross-over study, where participants served as their own controls, i.e. all underwent SIC with and without co-exposure to ozone in a human exposure chamber system consisting of a $79 \mathrm{~m}^{2}$ and a $32 \mathrm{~m}^{2}$ chamber [7]. Ethical clearance was granted and informed consent was signed by all participants. All participants had an initial forced expiratory volume in $1 \mathrm{~s}\left(\mathrm{FEV}_{1}\right)$ above $70 \%$ of predicted, and underwent an unspecific bronchial methacholine challenge test with a maximum cumulated dose of $4.51 \mathrm{mg}$ methacholine bromide. No participants used antihistamines within $72 \mathrm{~h}$ prior to the SIC. Participants underwent SIC with birch $(\mathrm{n}=17)$ or grass allergen $(\mathrm{n}=19)$, depending on the clinically relevant sensitisation. Airflow, temperature, humidity, $\mathrm{CO}_{2}$ and ozone were monitored during SICs. Ozone was added to the ventilation system. Mean \pm SD ozone exposure level in the chamber throughout the study was $120.9 \pm 1.8 \mathrm{ppb}$. Participants were in the chamber for approximately $1 \mathrm{~h}$ prior to the SIC.

Doses from 1.4 to 5600 SQ-U (standardised quality units) allergen extracts (ALK-Abelló) of Phleum pratense or Betula verrucosa were administered with a Spira Dosimeter nebuliser and $\mathrm{FEV}_{1}$ was measured 15 min after each inhalation with a handheld MicroDL spirometer. SICs were performed according to the protocol outlined by $\emptyset_{\mathrm{RBY}}$ [8]. At least 14 days passed between each SIC to avoid a carry-over effect. All study days were outside the relevant pollen seasons.

We estimated the bronchoconstrictive response by applying a novel approach using a non-linear four-parameter logistic regression model to assess the provocative dose of allergen causing a $20 \%$ drop in $\mathrm{FEV}_{1}\left(\mathrm{PD}_{20}\right)$. The model included all $\mathrm{FEV}_{1}$ observations and was applied to the $\mathrm{FEV}_{1}$ data using the log

@ERSpublications

Exposure to low, naturally occurring, levels of ozone do not alter the bronchial response profile to pollen allergen, or lower the $\mathrm{PD}_{20}$ in atopic individuals, estimated by applying a novel non-linear model approach http://bit.ly/2XQjzwI

Cite this article as: Ørby PV, Bønløkke JH, Bibby BM, et al. Dose-response curves for co-exposure inhalation challenges with ozone and pollen allergen. Eur Respir J 2019; 54: 1801208 [https://doi.org/ 10.1183/13993003.01208-2018]. 
cumulative dose as independent variable:

$$
\operatorname{FEV}_{1}(x)=a+\frac{b-a}{1+\exp \frac{c-x}{d}}
$$

Where $x$ is $\log$ cumulative dose, $a$ is baseline $\mathrm{FEV}_{1}, b$ is $\mathrm{FEV}_{1}$ at maximal log cumulative dose, $c$ is the log cumulative dose corresponding to half the decrease in $\mathrm{FEV}_{1}$ (the inflection point), and $d$ is a scaling parameter. Repeated measurements for each subject were taken into account by including random subject, and exposure within subject, effects. All results were obtained using the nlme package in the R Program. Statistical significance was set at $\mathrm{p}=0.05$.

Non-specific bronchial methacholine challenge test was positive for 14 participants and of these, $40 \%$ dropped below $20 \%$ only after the highest dose. The methacholine $\mathrm{PD}_{20}$ estimate for all participants was $4.4 \mathrm{mg}$ (95\% CI 2.8-6.8 mg) methacholine bromide.

The non-linear regression model used to assess individual SIC profiles showed a good fit to measured data, resulting in reliable estimates of both the profiles and $\mathrm{PD}_{20}$, and with no systematic errors in the residuals. For grass, 15 of the 19 participants had lower $\mathrm{PD}_{20}$ when co-exposed to ozone. For birch, this was true for nine of the 17 participants. However, differences between $\mathrm{PD}_{20}$ for allergen alone and co-exposure to ozone was not statistically significant (birch, $\mathrm{p}=0.35$; grass, $\mathrm{p}=0.14$ ). Also, no statistically significant difference was seen for the modelled SIC profiles. Figure 1 shows the combined modelled FEV by $\log$ cumulated dose of allergen curves.

Compared to natural setting studies, exposure chamber studies offer well-controlled ozone levels, and assure elimination of all other exposures. However, only short-term exposures are feasible. Our negative finding may be due to the short exposure time to lower levels of ozone; however, this indicates that short term exposure to ozone levels slightly higher than normally encountered in Denmark does not increase bronchial reactivity in pollen-sensitised individuals.

Previous studies have shown inconsistent results [5, 6, 9-12], and it has been suggested that there is no lower limit for the effects of ozone on the respiratory system [13]. If true, those effects might not be an acute response as investigated in this study, but due to more prolonged exposures.

In Denmark, an important source of $\mathrm{O}_{3}$ is the transport of air masses from southern Europe [14]. The potential effects of simultaneous co-exposure to pollen and $\mathrm{O}_{3}$ may therefore be higher in central or southern Europe where ozone concentrations are generally higher.

Any combination of the timing of exposure to pollen and ozone could increase the effect, and high levels of ozone may be of relevance to pollen-sensitised individuals before, during or after pollen allergen exposure. Exposure to ozone prior to allergen may induce an increased acute or late phase reaction [9] induced by inflammation and mucosal irritation, facilitating an increased reactivity to pollen [5, 9]. Exposure to high levels of allergen could also induce inflammation, rendering the airways more susceptible to a later ozone exposure.
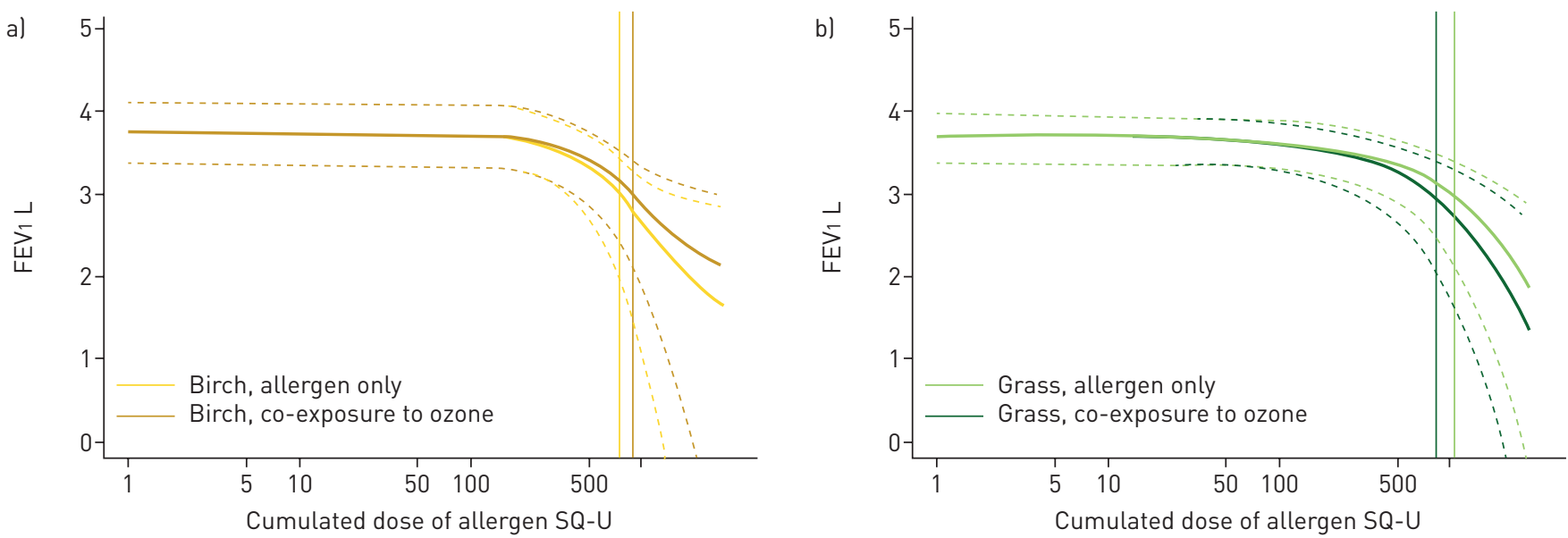

FIGURE 1 Modelled dose-response relationships for al birch and b) grass with $95 \%$ confidence intervals. FEV F $_{1}$ forced expiratory volume in 1 s; SQ-U: standardised quality units. Vertical lines indicate combined modelled provocative dose of allergen causing a $20 \%$ drop in $\mathrm{FEV}_{1}$ estimates. 
The modelled $\mathrm{PD}_{20}$ clearly showed individual differences in the response. However, it appears that there is an overall typical pattern of response, similar for both birch and grass pollen, and similar with and without co-exposure to ozone. The curves are robust until reaching $\mathrm{PD}_{20}$ levels, and to our knowledge, we are the first to show that log dose-response curves for grass and birch allergen have a similar response pattern independent of ozone exposure. Of note, we did not see a difference between reactions to grass and birch allergens. This is in contrast to previous findings in children where exposure to grass, but not to birch pollen, was associated to declining lung function [15]. However, these findings could be related to the longer exposure for ambient grass pollen compared to birch, whereas we applied identical exposures for the two allergens.

In conclusion, we found no difference in bronchoconstriction measured as modelled dose-response profiles and modelled $\mathrm{PD}_{20}$ between solely allergen exposure and co-exposure to allergen and natural levels of ozone. We demonstrate that a non-linear four-parameter logistic model provides a good fit to the measured data, allowing for calculation of $\mathrm{PD}_{20}$ based on all points on the dose-response curve. Participants in this study were only exposed for a short time to low levels of ozone. Still, our results indicate that brief exposure to ozone at levels normally encountered in Denmark does not increase bronchial reactivity in pollen-sensitised individuals.

Pia Viuf Ørby ${ }^{1,2}$, Jakob Hjort Bønløkke $\oplus^{1,3}$, Bo Martin Bibby ${ }^{1}$, Peter Ravn ${ }^{1}$, Ole Hertel ${ }^{2}$, Torben Sigsgaard ${ }^{1}$ and Vivi Schlünssen ${ }^{1,4}$

${ }^{1}$ Dept of Public Health, Aarhus University, Aarhus, Denmark. ${ }^{2}$ Dept of Environmental Science, Aarhus University, Roskilde, Denmark. ${ }^{3}$ Dept of Occupational and Environmental Medicine, Danish Ramazzini Centre, Aalborg University Hospital, Aalborg, Denmark. ${ }^{4}$ National Research Center for the Working Environment, Copenhagen, Denmark.

Correspondence: Pia Viuf Ørby, Dept of Environmental Science (ENVS), Aarhus University, PO Box 358, Frederiksborgvej 399, 4000 Roskilde, Denmark. E-mail: piv@ph.au.dk

Received: Nov 232017 | Accepted after revision: April 152019

This study is registered as a clinical trial by the Scientific Ethics Committee for Central Denmark Region (M-20090215). No data sharing provision has been made for this trial.

Conflict of interest: None declared.

\section{References}

Kelly FJ, Fussell JC. Air pollution and airway disease. Clin Exp Allergy 2011; 41: 1059-1071.

2 Schiavoni G, D'Amato G, Afferni C. The dangerous liaison between pollens and pollution in respiratory allergy. Ann Allergy Asthma Immunol 2017; 118: 269-275.

3 Ørby PV, Peel RG, Skjøth CA, et al. An assessment of the potential for co-exposure to allergenic pollen and air pollution in Copenhagen, Denmark. Urban Climate 2015; 14: 457-474.

4 Hernandez ML, Lay JC, Harris B, et al. Atopic asthmatic subjects but not atopic subjects without asthma have enhanced inflammatory response to ozone. J Allergy Clin Immunol 2010; 126: 537-544.

5 Molfino NA, Wright SC, Katz I, et al. Effect of low concentrations of ozone on inhaled allergen responses in asthmatic subjects. Lancet 1991; 338: 199-203.

6 Chen LL, Tager IB, Peden DB, et al. Effect of ozone exposure on airway responses to inhaled allergen in asthmatic subjects. Chest 2004; 125: 2328-2335.

7 Riddervold IS, Bønløkke JH, Mølhave L, et al. Wood smoke in a controlled exposure experiment with human volunteers. Inhal Toxicol 2011; 23: 277-288.

8 Ørby PV. Cross-disciplinary studies on pollen in health and environmental sciences. PhD dissertation, Aarhus University, 2017.

9 Jörres R, Nowak D, Magnussen H. The effect of ozone exposure on allergen responsiveness in subjects with asthma or rhinitis. Am J Respir Crit Care Med 1996; 153: 56-64.

10 Kehrl HR, Peden DB, Ball B, et al. Increased specific airway reactivity of persons with mild allergic asthma after 7.6 hours of exposure to 0.16 ppm ozone. J Allergy Clin Immunol 1999; 104: 1198-1204.

11 Hanania NA, Tarlo SM, Silverman F, et al. Effect of exposure to low levels of ozone on the response to inhaled allergen in allergic asthmatic patients. Chest 1998; 114: 752-756.

12 Ball BA, Folinsbee LJ, Peden DP, et al. Allergen bronchoprovocation of patients with mild allergic asthma after ozone exposure. J Allergy Clin Immunol 1996; 98: 563-572.

13 Van Bree L, Marra M, Van Scheindelen HJ, et al. Dose-effect models for ozone. Toxicol Lett 1995; 82-83: 317-321.

14 Bloss W. Atmospheric chemical processes of importance in cities; air quality in urban environments. $R$ Soc Chem 2009: 42-64.

15 Gruzieva O, Pershagen G, Wickman M, et al. Exposure to grass pollen - but not birch pollen - affects lung function in Swedish children. Allergy 2015; 70: 1181-1183. 